\title{
HPLC-DAD-APCI-MS as a Tool for Carotenoid Assessment of Wild and Cultivated Cherry Tomatoes
}

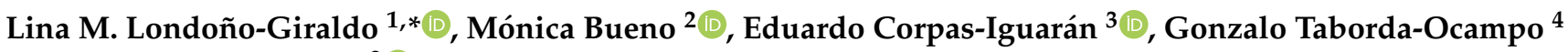 \\ and Alejandro Cifuentes ${ }^{2}$ (D) \\ 1 Grupo de Investigación MICROBIOTEC, Facultad de Ciencias de la Salud, Universidad Libre Pereira, \\ Pereira 660001, Colombia \\ 2 Laboratory of Foodomics, Institute of Food Science Research (CIAL, CSIC-UAM), Calle Nicolás Cabrera 9, \\ 28049 Madrid, Spain; monica.bueno@csic.es (M.B.); a.cifuentes@csic.es (A.C.) \\ 3 Grupo de Investigación GIMIBAG, Universidad Católica de Manizales, Manizales 170004, Colombia; \\ ecorpas@ucm.edu.co \\ 4 Grupo de Investigación GICTA, Departamento de Química, Universidad de Caldas, \\ Manizales 170004, Colombia; gtaborda@ucaldas.edu.co \\ * Correspondence: linam.londonog@unilibre.edu.co; Tel.: +57-3162506353
}

check for

updates

Citation: Londoño-Giraldo, L.M.; Bueno, M.; Corpas-Iguarán, E.;

Taborda-Ocampo, G.; Cifuentes, A. HPLC-DAD-APCI-MS as a Tool for Carotenoid Assessment of Wild and Cultivated Cherry Tomatoes. Horticulturae 2021, 7, 272. https:// doi.org/10.3390/horticulturae7090272

Academic Editor: Hanne

Kristine Sivertsen

Received: 8 July 2021

Accepted: 23 August 2021

Published: 31 August 2021

Publisher's Note: MDPI stays neutral with regard to jurisdictional claims in published maps and institutional affiliations.

Copyright: (c) 2021 by the authors. Licensee MDPI, Basel, Switzerland. This article is an open access article distributed under the terms and conditions of the Creative Commons Attribution (CC BY) license (https:/ / creativecommons.org/licenses/by/ $4.0 /)$.

\begin{abstract}
Carotenoids are naturally occurring fat-soluble pigments found in many organisms. Because of their extensively conjugated carbon-carbon double bond system, carotenoids are potent antioxidants. Although the most abundant carotenoid and best singlet oxygen quencher found in red tomatoes is lycopene, carotenoid profiles may vary between genotypes. The objective of this work was to perform carotenoid profile indentification using HPLC-DAD-APCI-MS in ten wild cherry tomato accessions and one cultivated tomato. A mixture of hexane/acetone/ethanol (50:25:25) and $0.1 \%$ BHT was used for carotenoid extraction. For separation, a C30 column at $30{ }^{\circ} \mathrm{C}$ with a gradient consisting of methanol, methyl-tert-butyl ether, and water was used for their analysis. Ten major carotenoids were quantified within cherry tomato samples. All accessions present different profiles and quantities of carotenoids. Wild red tomatoes had more lycopene content that commercial tomato, whereas yellow tomatoes present no lycopene. From a functional viewpoint, higher concentrations of carotenoids that could play an antioxidant activity were measured from accessions IAC401, IAC426, LA1480, IAC391, and LA2692. This trait means that these germplasms may be targets for commercial activities. To the best of our knowledge, this is the first time that HPLC-DAD-APCI-MS has been used to analyze these accessions of wild cherry tomatoes that are both functionally promising and suitable for projects with social implementation at a local scale.
\end{abstract}

Keywords: $\beta$-carotene; carotenoids; cherry tomato; HPLC-DAD-APCI-MS; lycopene; lutein

\section{Introduction}

Carotenoids are the second most abundant naturally occurring pigments on earth, with more than 750 members ranging from colorless to yellow, orange, and red colors, with variations reflected in many fruits, flowers, and vegetables [1]. These pigments, mainly composed of C40 lipophilic isoprenoids, protect cells from reactive radicals and prevent lipid peroxidation [2]. It is well known that carotenoids have numerous beneficial effects on human health due to their high antioxidant properties and their efficiency in neutralizing superoxide radical anions. Carotenoids play a key role in the protection against cardiovascular disease, obesity, diabetes and lung, head, neck, and prostate cancer [3]. Furthermore, they can modulate growth factors, intracellular signaling pathways, cell differentiation, and immune responses [4]. Carotenoids are also precursors of vitamin A and can reinforce the defense against UV radiation $[5,6]$.

Since the human body does not synthesize carotenoids endogenously, diet is the only way of getting these compounds [3]. The most important carotenoids for humans include 
lycopene, lutein, zeaxanthin and $\beta$-cryptoxanthin [7]. Nutritionally, $\alpha-, \beta-, \gamma$-carotene as well as $\alpha$ and $\beta$-cryptoxanthin are considered provitamin A carotenoids (pVACs) [8]. Lycopene has been shown to be the most powerful antioxidant by in vitro experiments [7]. Lycopene is an eligible target for electrophilic reagent because its polyene structure provides an electron-rich system, performing high reactivity towards oxygen and free radicals [3,9]. Regarding the human diet, tomatoes are considered a major source of carotenoids. Of the 25 carotenoids present in the human bloodstream, most of the relevant carotenoids are present only in fresh and processed tomatoes [10].

All-trans-lycopene is the major coloring principle in tomato extract, however, minor amounts of cis-isomers and other carotenoids and related substances including $\beta$-carotene, phytofluene, phytoene, and tocopherols are also present. Lycopene content in tomato typically ranges from 70 to $130 \mathrm{mg} / \mathrm{kg}$ and depends on the variety, geographic location, technique of cultivation, climatic conditions, degree of ripeness, and domestication conditions of tomato fruits [9].

The most studied domestication trait associated with tomato cultivation is the size and shape of the fruit [11]. Nevertheless, there are several agronomically and chemically important traits that have been compromised in the current cultivars. For instance, during tomato ripening, lycopene and other carotenoid biosynthesis is associated with chromoplast development, which is a process controlled at different levels (proteins of metabolic pathways at the transcriptional level, and modifications of sink structures at a post-transcriptional stage) [11,12]. These findings have been considered crucial factors in determining the levels and stability of these pigments among tomato fruits. Consequently, there is a huge difference between the genotypes and phenotypes of wild tomatoes versus cultivated tomatoes, with the latter being decimated as a result of domestication [13].

As a consequence of carotenoids' chemical and physical properties, the established analytical method for the characterization of carotenoids is high-performance liquid chromatography (HPLC) coupled with UV-Vis absorbance and mass spectrometry (MS) detectors. The several conjugated double bonds along the carbon skeleton of carotenoids present intense absorption bands in the visible region within 400-500 $\mathrm{nm}$ [5].

Therefore, considering the complex chemical composition of tomato carotenoids, their UV-Vis absorption properties, and taking into account the diversity and concentration of carotenoids within wild tomatoes compared to commercial tomatoes, this study aimed to analyze the carotenoid profile of ten wild cherry tomato accessions and one cultivated tomato using HPLC coupled with APCI interphase and diode array (DAD) and MS as a specific platform for carotenoid analysis. Furthermore, relationships between different wild tomato accessions, commercial tomatoes, and their chemical composition were carried out using multivariate statistical tools.

\section{Materials and Methods}

\subsection{Plant Material and Growing Conditions}

Ten accessions of S. lycopersicum var. cerasiforme (IAC391, IAC401, IAC2076, IAC1624, IAC412, IAC426 (and its round fruit form IAC426R), LA1480, LA2692, and LA1705) and the fruits of one commercial cherry tomato obtained from a market were used. A description of the wild germplasm is available in [14]. Seedlings were grown in a greenhouse using a hydroponic system in a random design with four replicates per accession. The plants were kept at the Botanical Garden in the Universidad de Caldas, Manizales-Caldas, Colombia. The tomatoes were picked randomly from plants in each plot. More specifications of tomato growing conditions and time and stage of tomato fruit picking is available in [15].

\subsection{Samples and Reagents}

Tomato fruits were dried at $70{ }^{\circ} \mathrm{C}$ and then were frozen and ground in liquid nitrogen. After that, tomato powder was lyophilized for three days. Freeze-dried tomato powder samples were stored in the dark at a temperature of $-18^{\circ} \mathrm{C}$ until utilization. HPLC grade solvents used include acetone purchased from Sigma-Aldrich (Madrid, Spain), hexane 
from JT Baker (Madrid, Spain), whereas ethanol, methyl tert-butyl ether (MTBE), and methanol were acquired from VWR chemicals (Barcelona, Spain). Water was purified using a Milli-Q system (Millipore Corp, Billerica, MA, USA). Tetrahydrofuran (THF) was obtained from Macron Fine Chemicals (Pensilvania, USA), while butylated hydroxytoluene (BHT) and lycopene ( $\geq 97 \%)$, all-trans- $\beta$-carotene $(\geq 97 \%)$, lutein $(\geq 96 \%)$ and zeaxanthin $(\geq 95 \%)$ standards were purchased from Sigma-Aldrich.

\subsection{Carotenoid Conventional Extraction Method}

A conventional extraction, using hexane:acetone:ethanol (50:25:25 v:v:v) and 0.1\% $(w / v)$ BHT was carried out with duplicate to determine the total extractable carotenoids in wild cherry tomatoes using a method proposed elsewhere [16] with some modifications. Briefly, $1 \mathrm{~g}$ of lyophilized tomato powder was mixed with $20 \mathrm{~mL}$ of the solvent mixture and was shaken for $1 \mathrm{~h}$ in the dark at $250 \mathrm{rpm}$. After centrifugation $\left(10,000 \mathrm{rpm}\right.$ at $4{ }^{\circ} \mathrm{C}$ for $10 \mathrm{~min}$ ), the supernatant was collected. This process was repeated three times. The supernatants were collected, and to evaporate the solvents an $\mathrm{N}_{2}$ stream was used. Dried extracts were weighted and stored in the dark at $-20^{\circ} \mathrm{C}$.

\subsection{HPLC-DAD-MS Analysis}

An Agilent HP 1100 series liquid chromatograph (Santa Clara, CA, USA) equipped with a diode-array detector (DAD) was used for quantitative carotenoid analyses. YMCC30 reversed-phase column $(250 \mathrm{~mm} \times 4.6 \mathrm{~mm}$ i.d., $5-\mu \mathrm{m}$ particle size; YMC Europe, Schermbeck, Germany) and a precolumn YMC-C30 (10 $\mathrm{mm} \times 4 \mathrm{~mm}$ i.d., $5-\mu \mathrm{m}$ particle size) was used for separation as reported by Bueno et al. (2020) [17]. In liquid chromatography, the mobile phase A consisting of a solution of methanol:MTBE:water (90:7:3, v:v:v) was used as, while the mobile phase $B$ consisted on methanol:MTBE (10:90, v:v) with a gradient of: $0 \mathrm{~min}, 95 \% \mathrm{~A} ; 5 \mathrm{~min}, 70 \% \mathrm{~A} ; 10 \mathrm{~min}, 50 \% \mathrm{~A} ; 15 \mathrm{~min}, 20 \% \mathrm{~A} ; 20 \mathrm{~min}, 0 \% \mathrm{~A} ; 27 \mathrm{~min}$, $95 \% \mathrm{~A}$, with a run time of $33 \mathrm{~min}$ and a flow rate of $0.8 \mathrm{~mL} / \mathrm{min}$. The samples were dissolved in THF:methanol (50:50) at a concentration of $20 \mathrm{mg} / \mathrm{mL}$ and filtered through $0.45 \mu \mathrm{m}$ nylon filters. Subsequently, a volume of $10 \mu \mathrm{L}$ was injected. Absorption spectra were recorded from 240 to $770 \mathrm{~nm}$ (peak width $0.1 \mathrm{~min}(2 \mathrm{~s})$, slit $4 \mathrm{~nm}$ ) and quantification was carried out at 280 and $450 \mathrm{~nm}$ using DAD. The instrument was controlled by LC Chem Station 3D Software Rev. B04.03 (Agilent Technologies, Santa Clara, CA, USA). The same instrument was directly coupled at the exit of the DAD to an ion trap mass spectrometer (Agilent ion trap 6320, Agilent Technologies) via an atmospheric pressure chemical ionization (APCI) interface, as was described elsewhere [18]. Analyses were conducted under positive ionization mode using the following parameters: capillary voltage, $-3.5 \mathrm{kV}$; drying temperature, $350{ }^{\circ} \mathrm{C}$; vaporizer temperature, $400{ }^{\circ} \mathrm{C}$; drying gas flow rate, $5 \mathrm{~L} / \mathrm{min}$; nebulizer gas pressure, $60 \mathrm{psi}$; corona current (which sets the discharge amperage for the APCI source), $4000 \mathrm{nA}$. Full scan spectrum was acquired in the range from $\mathrm{m} / \mathrm{z} 150$ to 1300 .

Carotenoid identification was performed by comparison with available standards, known absorption spectra, $[\mathrm{M}+\mathrm{H}]^{+}$data, retention times, and elution orders reported in the literature as in [19]. For the calibration curves, stock solutions of zeaxanthin and lutein were prepared in ethanol at a concentration of $2 \mathrm{mg} / \mathrm{mL}$ and THF $(1.5 \mathrm{mg} / \mathrm{mL})$. For dissolving $\beta$-carotene and lycopene, six to eight serial dilutions were performed and injected in triplicate. The linear regression equation and the correlation coefficient $\left(\mathrm{r}^{2}\right)$ were then obtained by plotting the concentration of the injected solutions versus the peak area (Table 1). For this purpose, Microsoft ${ }^{\circledR}$ Excel 365 (Microsoft Corporation, Redmond, WA, USA) was used. Moreover, Table 1 also collects detection and quantification limits. Standards of the rest of the compounds identified are not commercially available; therefore, quantification of different carotene and lycopene isomers was done using the all-trans- $\beta$ carotene and lycopene standards, respectively, assuming the response factor would be the same. Unidentified carotenoids were also quantified using the all-trans- $\beta$-carotene calibration curve. 
Table 1. HPLC-UV/Vis calibration curve parameters of carotenoid standards employed for quantification.

\begin{tabular}{ccccc}
\hline Carotenoids & $\mathbf{r}^{2}$ & $\begin{array}{c}\text { Linearity Range } \\
(\mu \mathrm{g} / \mathrm{mL})\end{array}$ & $\begin{array}{c}\text { LOD } \\
(\mu \mathrm{g} / \mathrm{mL})\end{array}$ & $\begin{array}{c}\text { LOQ } \\
(\mu \mathrm{g} / \mathrm{mL})\end{array}$ \\
\hline Lutein & 0.993 & $4.3-51.2$ & $3.66 \times 10^{-2}$ & $1.22 \times 10^{-1}$ \\
Zeaxanthin & 0.995 & $2.3-61.2$ & $5.18 \times 10^{-3}$ & $1.72 \times 10^{-2}$ \\
all-trans- $\beta$-carotene & 1.000 & $0.2-26.1$ & $8.11 \times 10^{-2}$ & $2.70 \times 10^{-1}$ \\
Lycopene & 0.999 & $1.3-99.6$ & $7.32 \times 10^{-2}$ & $2.44 \times 10^{-1}$ \\
\hline
\end{tabular}

$\mathrm{r}^{2}$ : square of correlation coefficient; LOD: limit of detection; LOQ: limit of quantification.

\subsection{Statistical Analysis}

IBM SPSS Statistics software v.19 was employed for data elaboration and statistical analysis using a level of significance set to $95 \%$. One-way analysis of variance (ANOVA) was employed to compare carotenoid concentration between accessions. Duncan's multiple range teste was applied to determine significant differences among accessions mean values at a significance level of $p<0.05$. A principal components analysis (PCA) was developed using the statistical software The Unscrambler 9.7 (CAMO, Trondheim, Norway). The PCA was carried out to demonstrate the unsupervised discrimination between accessions according to their carotenoid composition. The PCA was done on standard scaled data to prevent features with large variances from having dominant explanatory power.

\section{Results}

\subsection{Carotenoid Characterization by HPLC-DAD-MS}

In this work, the proposed method based on liquid chromatography coupled with diode array and mass spectrometry detection (HPLC-DAD-MS) allowed the identification and quantification of carotenoids in cherry tomatoes. Thus, a tentative identification of nine compounds shown in Table 2 was accomplished by combining the information provided by UV/Vis spectra from DAD, $[\mathrm{M}+\mathrm{H}]^{+}$data from mass spectrometry detector and bibliographic data. Chromatographic profiles of wild cherry tomato samples are shown in Figure 1. Peak number 9 comes out as the most relevant carotenoid in all the tomato accessions, followed by number 5 (see Figure 1A,D). Both carotenoids were confirmed by the injection of pure standards as all-trans- $\beta$-carotene (peak 5 ) and lycopene (peak 9), and peaks numbers 1 and 2 were confirmed as lutein and zeaxanthin, respectively, by injecting the standards.

Table 2. Pigments detected in cherry tomato accessions.

\begin{tabular}{|c|c|c|c|c|}
\hline Peak & Carotenoids & RT (min) & UV/Vis Max (nm) & {$[\mathbf{M}+\mathbf{H}]^{+} m / z$} \\
\hline 1 & Lutein $^{\mathrm{a}}$ & 10.11 & 445,474 & 569.4 \\
\hline 2 & Zeaxanthin $^{\mathrm{a}}$ & 10.72 & $425,449,476$ & 569.6 \\
\hline 3 & phytoene & 11.68 & 281 & \\
\hline 4 & all-trans- $\alpha$-carotene & 15.36 & $424,446,475$ & 537.4 \\
\hline 5 & all-trans- $\beta$-carotene ${ }^{a}$ & 16.36 & 452,477 & 537.6 \\
\hline 6 & carotenoid 1 & 16.90 & $426,448,475$ & 537.5 \\
\hline 7 & $\delta$-carotene & 17.49 & $432,457,488$ & 537.5 \\
\hline 8 & 1,2-dihydrolycopene & 20.75 & $440,468,502$ & 537.4 \\
\hline 9 & trans-lycopene ${ }^{\mathrm{a}}$ & 22.16 & $446,472,503$ & 537.4 \\
\hline
\end{tabular}

\footnotetext{
a Identification corroborated by comparison with commercial standards; RT: retention time.
} 


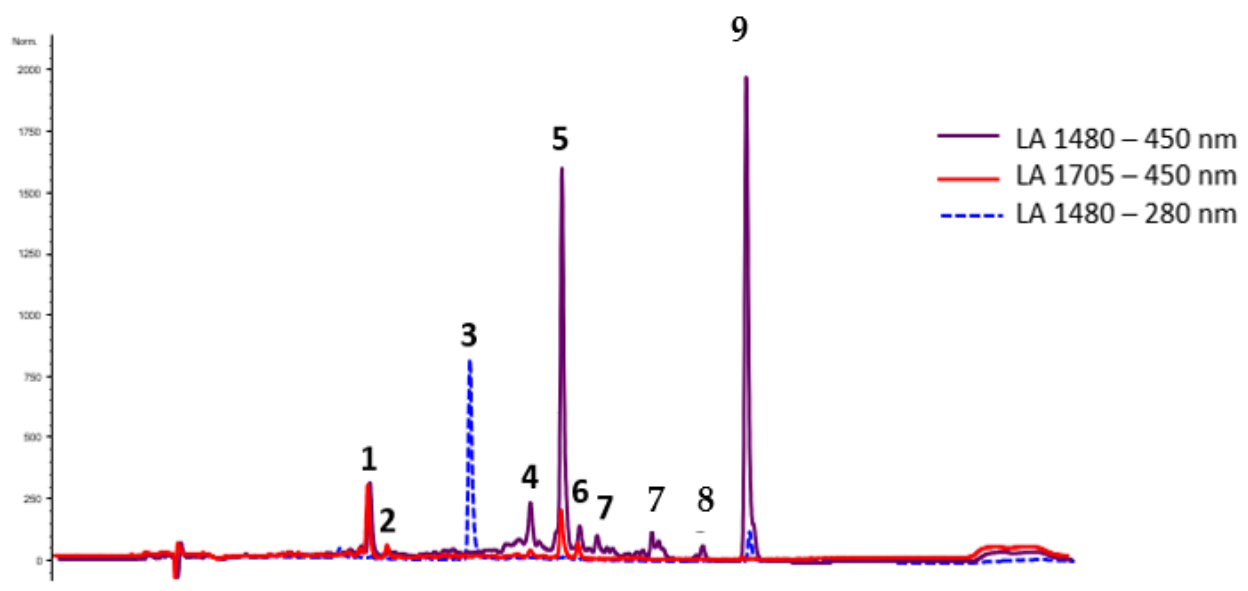

(A)

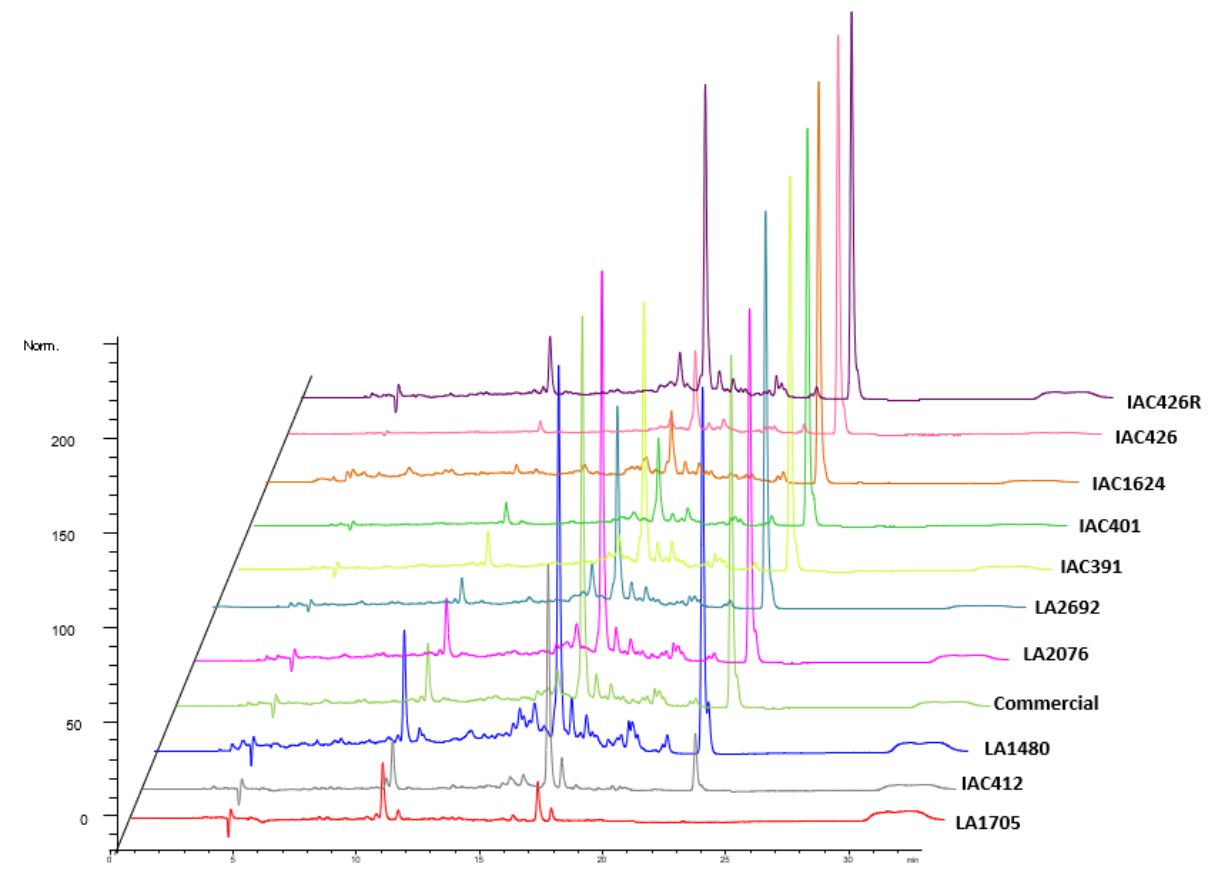

(B)

Figure 1. Carotenoid profiles of wild cherry tomato samples. (A). Chromatograms of carotenoids analyzed in wild cherry tomatoes under two wavelengths (280 and $450 \mathrm{~nm}$ ). For peak assignment, see Table 1. (B). Chromatograms of cherry tomatoes wild accessions generated by HPLC-DAD at $450 \mathrm{~nm}$.

UV-Vis spectra data available for phytoene, $\alpha$-carotene, $\delta$-carotene, and 1,2-dihydrolycopene (peaks 3, 4, 7 and 8, respectively) were used for their identification [20]; (see Table 2 and Figure 1A). Furthermore, these compounds could be characterized in terms of $[\mathrm{M}+\mathrm{H}]^{+}$and compared with different carotenoid information available in tomato and other matrices [21-24]; nevertheless phytoene (peak 3) $[\mathrm{M}+\mathrm{H}]^{+}$data could not be obtained successfully. Peak number 6 presented the typical spectrum of carotenes and therefore has been designated as unknown carotenoid 1 . It was characterized in terms of $[\mathrm{M}+\mathrm{H}]^{+}$; however, its tentative identification was difficult. The quantitative composition of cherry tomatoes and commercial tomato extracts was estimated by interpolation of the calibration curves created with the available commercial standards as described in the Material and Methods section. The quantitative results of each compound are reported in Table 3. 


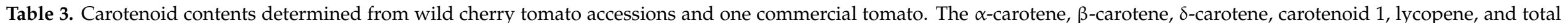

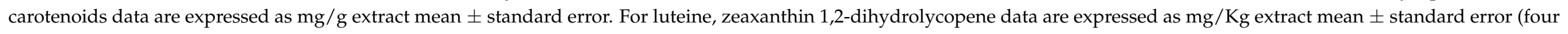

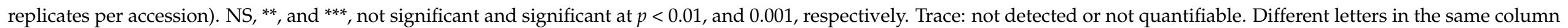
indicate significant differences $(p<0.05)$ between accessions (Duncan's test).

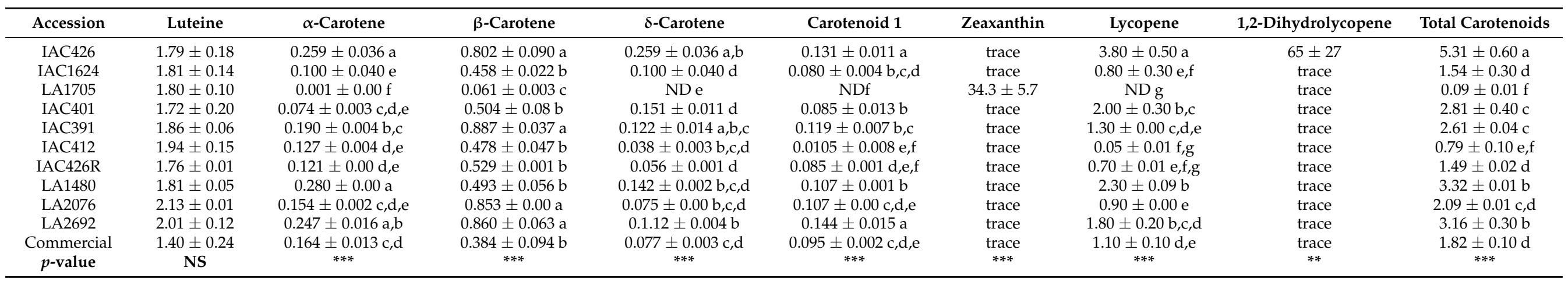


This table allows for the fast quantitative comparison of carotenoid content, which can already be seen in Figure 1B in a qualitative way among accessions and with the commercial cherry tomato. Lycopene is the most abundant pigment within red fruits, and therefore its values are high in most of the analyzed tomatoes, as expected. It is worth mentioning the significantly high levels of lycopene found in IAC426, which are almost three times higher than the average of the studied tomatoes and accounts for more than $70 \%$ of the carotenoids in this accession. Moreover, this accession is the only one that showed quantifiable values of 1,2-dihydrolycopene and the highest amount of total carotenoid content with respect to the other accessions.

On the other hand, the small presence or absence of lycopene is observed in non-red tomatoes, IAC412 (pink tomato) and LA1705 (yellow tomato), respectively. For all-trans$\beta$-carotene, levels ranged from 0.10 to $0.90 \mathrm{mg} / \mathrm{g}$ in the analyzed tomatoes, becoming the second most prevalent carotenoid in the samples. The sum of lycopene and all-trans$\beta$-carotene accounts for $83 \pm 6 \%$ of the average total carotenoid content. Its relevance together with that of lycopene is because their accumulation produces the color change in tomato, acting as a visual clue of fruit ripening [25]. Even in the accession with the least amount of all-trans- $\beta$-carotene, LA1705, this compound is the one that dominates the carotenoid profile, as well as for IAC412 accession. Both accessions showed percentages of all-trans- $\beta$-carotene greater than $60 \%$ of the total carotenoid content.

Other carotenoids like $\alpha$-carotene, $\gamma$-carotene, and the unknown carotenoid were present in nearly all accessions in appreciable proportions with significant differences between them, while lutein occurrence is much lower, and no statistical differences were found. A special mention should be made for zeaxanthin, a carotenoid whose presence is related to yellow pigmentation in fruits [26]. This compound was only detected in LA1705, the yellow tomato.

\subsection{Relationship between Carotenoid Levels and Tomato Accessions}

Figure 2 shows the relationship between carotenoid content in the different wild accessions and commercial tomato. The PCA plot retains $85 \%$ of the explained variability. As shown in the figure, PC1 classifies the samples attending to their total content of carotenoids, providing a clear separation between samples with amounts lower than $2 \mathrm{mg}$ of carotenoids/g extract (on the left), from the ones that provide amounts higher than $2 \mathrm{mg} / \mathrm{g}$ extract (on the right). On the other hand, PC2 sorts by types of carotenoids, dominated by the presence of 1,2-dihydrolycopene and lutein. The plot shows that LA1705 and commercial tomato are very different tomatoes with respect to the other samples analyzed, both located in the upper-left quadrant. PCA is also able to differentiate between IAC426 and its round fruit named IAC426R, both placed in opposite quadrants. In general, samples are classified into three groups. The first one consisting solely of LA1705, obviously distinguished by the presence of zeaxanthin (Figure 2, orange circle). The second is composed of accessions IAC426, LA1480, IAC401, and commercial tomato, determined mainly by lycopene (Figure 2, purple square). Additionally, the third group with LA2692, LA2076, IAC391, IAC412, IAC426R, and IAC1624 (Figure 2, green circle) was influenced mainly by $\beta$-carotene and lutein. 


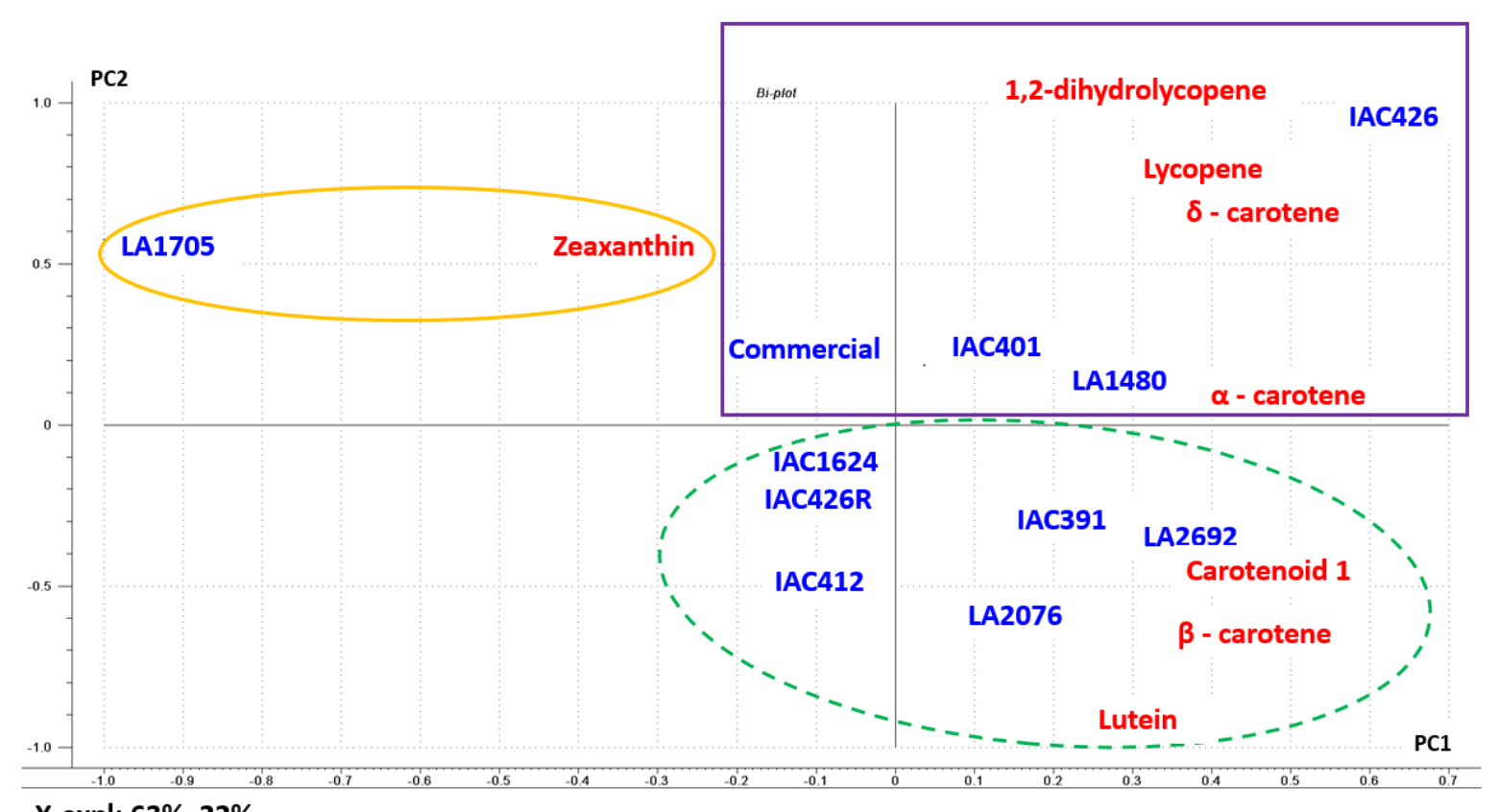

X-expl: $63 \%, 22 \%$

Figure 2. Principal component analysis (PCA) of carotenoids determined in ten wild cherry tomato fruits accessions and commercial cherry tomato.

\section{Discussion}

\subsection{Carotenoid Characterization by HPLC-DAD-MS}

The formation and presence of carotenoids in fruits can be quite complex, since it depends on the drastic changes suffered in both the content and the composition not only during ripening but also during the development stage [12].

Dzakovich and coworkers listed ten carotenoids in tomato (lutein, lycopene, cislycopene, $\gamma$-carotene, cis- $\zeta$-carotene, $\zeta$-carotene, $\beta$-carotene, phytofluene, neurosporene, and phytoene) [23]. According to our findings, in the wild accessions studied some isomers of carotenes, cis-lycopene, neurosporene, and phytofluene were missing. Moreover, other carotenoids were identified, which could be done by the use of APCI as interface with the MS and the use of C30 column for separation, which is most suitable for the detection of higher molecular mass compounds [27]. The reason that missing carotenoids could be due to their metabolic pathway and the instability of these molecules during their biosynthesis or the polarity degree of some carotenoids depending on the extraction method. Hence, carotenoid profiles can vary, especially in minor carotenoids depending on the type of tomato. This information can also indicate that carotenoid 1 could be a carotene isomer such as $\gamma$-carotene or $\zeta$-carotene.

As stated above, tomato domestication was mainly focused on increasing culture yield and fruit size. In addition to that and based on market requirements, a few commercial attributes were integrated in cultivated tomatoes, such as palatability and total soluble solids (TSS) [8]. The former is very related with carotenoid composition because some of the main tomato flavor volatiles come from carotenoid degradation [26]. For instance, $\alpha$-citral (geranial), $\alpha$-ionone, $\beta$-ionone, and farnesyl acetone are derived from lycopene, $\alpha$-carotene, $\delta$-carotene, and phytoene, respectively [28].

Specifically, the concentration of lycopene in tomato fruit is an important feature for the processing and fresh market industry, clearly to favor its tonality and consequently its appearance, which usually implies an increase in sales for food and beverages, cosmetics, and the nutraceutical industry [29]. For this reason, obtaining high levels of lycopene is a desirable trait in tomato and therefore, increasing lycopene content is a main objective in tomato breeding [30]. Nevertheless, as can be observed in Table 3, high levels of lycopene seem to be a natural trait in wild forms, since three accessions showed significantly higher 
values and another five accessions did not show significant differences in lycopene levels compared to commercial tomato.

Carotenoid species that accumulate in the mature chromoplasts are intermediaries in the pathway that essentially operates during the early stages of development, turning tomato fruit into a particular example [31]. Differential gene expression plays a major role in the accumulation of lycopene in tomato fruits by elevating the concentration of its biosynthetic enzymes and blocking the synthesis of enzymes that convert it to cyclic carotenoids. In red tomatoes, accumulation of lycopene begins at the 'breaker' stage of fruit ripening after the fruit has reached the 'mature green' stage. Following, GGDP synthase, phytoene synthase and phytoene desaturase increase significantly during the 'breaker' stage [32]. In contrast, lycopene $\beta$-cyclase and lycopene $\varepsilon$-cyclase decrease at the 'breaker' stage [31]. The accumulation of $\beta$ - or $\delta$-carotene is, instead, the result of the upregulation of one of the two lycopene cyclase genes. In particular, the dominant beta (B) mutation is responsible of the upregulation of CYCB preceding the transformation of lycopene to $\beta$-carotene, while delta (Del) mutants result from the upregulation of LCYE, involved in the production of $\delta$-carotene [33].

The fact that we found lutein and zeaxanthin in the same tomato accession (LA1705) is very interesting from a functional viewpoint. Lutein, usually extracted from marigold petals [34], and zeaxanthin are concentrated in the human macula, where they counteract the negative actions of UV-light and reactive oxygen species, thus delaying the onset of age-related macular degeneration and eye diseases [35].

Among crop species, the best candidate to replace marigold in lutein production is tomato. As mentioned before, synthesis of lutein in tomato fruit is hampered by a tightly regulated physiological mechanism that occurs before the start of ripening and involves the down-regulation of the genes encoding the lycopene $\beta$-and $\varepsilon$-cyclases [36]. This genetic control seems to be less strong in wild forms [11], which can be seen from the simultaneous presence of lutein and lycopene in nine of the ten wild accessions tested, since apparently lutein continues to be synthesized from lycopene even after tomato ripening has begun. The example of LA1705 is an extreme case, where the absence of lycopene as a pigment in combination with the presence of lutein, zeaxanthin, and all-trans- $\beta$-carotene indicate that $\beta$-and $\varepsilon$-cyclases are still very active in the ripened stage and therefore lycopene as a substrate is consumed entirely and does not accumulate.

Regarding the last column of Table 3, it can be seen that the commercial tomato has a total carotenoid content significantly lower than half of the analyzed wild accessions. This fact, together with the previously mentioned relationship between carotenoid content and tomato flavor, agrees with the flavor deficiencies observed in modern tomato cultivars explained by Sahu and Chattopadhyay (2017) [11]. Therefore, this work suggests that the different carotenoid profiles within wild tomato species depict a rich genetic resource still untapped for tomato improvement.

\subsection{Relationship between Carotenoid Levels and Tomato Accessions}

Promising accessions can then be chosen according to different features. For instance, IAC401 was selected as the most promising based on physicochemical parameters under a multicriteria decision analysis [37]. LA1480 was chosen as one of the most promising due to its flavor VOCs and sensorial descriptors [14]. In this case, genotype is the major determinant of variability in the carotenoid content within the analyzed cherry tomatoes, since all tomatoes were cultivated under the same conditions (light radiation intensity and quality, air- and fruit canopy temperature, $\mathrm{CO}_{2}$ concentration, and growing system). Most of these variants are the product of mutations in single genes coding for enzymes implicated in different phases of the carotenoid pathway. Some white and yellow tomato genotypes show a strong reduction in (or even a complete lack of) carotenoids due to a loss-of-function mutation of the PSY-1 (known as yellow-flesh, locus $r$ ) gene. This affects the blocking of the first step of the carotenoids pathway, resulting in pale-yellow flesh and more intensely yellow-colored skin phenotype typical of the ripe fruits [38]. The difference 
of carotenoids between tomatoes could be a very important trait and could be associated with other important plant conditions. In this regard, protection of fruit and fluidity of membrane during cold stress is favored by carotenes within membranes. Complementary, stability and lower fluidity under heat or light stress is favored by xanthophylls oriented perpendicular to the membrane surface [37]. Carotenoids may also act as powerful antioxidants, protecting fruit tissues from different stresses [12]. The content of lycopene in tomato fruit has been linked to reduced damage during cold storage [39]. Chilling stress may also reduce the lycopene content in this fruit [40], establishing a possible relationship between both factors.

\section{Conclusions}

A careful analysis of carotenoids of ten promising wild cherry tomatoes and a commercial cherry tomato has been presented using HPLC-APCI-DAD-MS. Lycopene and $\beta$-carotene are the main potential antioxidants retrieved. Additionally, other minor relevant antioxidants, such as lutein and zeaxanthin were found; the former detected in all samples. Higher levels of lycopene and $\beta$-carotene were found in wild tomatoes than in commercial samples. Accessions IAC401, IAC426, LA1480, IAC391, and LA2692 have significantly higher concentrations of carotenoids, which could play a key role in antioxidant activity. Our analysis revealed a diverse profile within wild tomato species, depicting a rich genetic resource still untapped for tomato improvement. Additionally, we confirmed with this technique the tendency of carotenoid concentration and diversity to decrease in commercial cherry tomatoes, probably as a product of domestication. As far as we know, this is the first time that very different wild tomato cherry accessions have been characterized in terms of carotenoids by HPLC-APCI-DAD-MS in order to generate social knowledge about the powerful antioxidant capacity of wild cherry tomatoes.

Author Contributions: Conceptualization, L.M.L.-G., M.B. and A.C.; methodology, L.M.L.-G. and M.B.; software, L.M.L.-G. and M.B.; validation, L.M.L.-G. and M.B; formal analysis, L.M.L.-G. and M.B; investigation, L.M.L.-G.; resources, A.C.; data curation, L.M.L.-G. and M.B.; writing-original draft preparation, L.M.L.-G. and M.B.; writing—review and editing, L.M.L.-G., M.B, E.C.-I., G.T.-O. and A.C.; visualization, L.M.L.-G. and M.B; supervision, A.C.; project administration, E.C.-I., G.T.-O. and A.C.; funding acquisition, E.C.-I., G.T.-O. and A.C. All authors have read and agreed to the published version of the manuscript.

Funding: This research was funded by MINISTERIO DE CIENCIA, TECNOLOGIA E INNOVACION (COLCIENCIAS) from the Colombian government, grant number 727 of 2015 to L.M.L.G. in the Call for National Doctorates. M.B. acknowledges MINECO for a "Juan de La Cierva-Formación" FJCI-201630902 and MICIU for the "Juan de La Cierva-Incorporación" IJC2018-037830-I postdoctoral grants.

Acknowledgments: We would like to thank the Foodomics lab's staff in CIAL for their support in all the processes of this research, and Universidad de Caldas.

Conflicts of Interest: The authors declare no conflict of interest.

\section{References}

1. Nisar, N.; Li, L.; Lu, S.; Khin, N.C.; Pogson, B.J. Carotenoid metabolism in plants. Mol. Plant 2014, 8, 68-82. [CrossRef]

2. Gong, M.; Bassi, A. Carotenoids from microalgae: A review of recent developments. Biotechnol. Adv. 2016, 34, 1396-1412. [CrossRef]

3. Fiedor, J.; Burda, K. Potential role of carotenoids as antioxidants in human health and disease. Nutrients 2014, 6, 466-488. [CrossRef] [PubMed]

4. Milani, A.; Basirnejad, M.; Shahbazi, S.; Bolhassani, A. Carotenoids: Biochemistry, pharmacology and treatment. Br. J. Pharmacol. 2017, 174, 1290-1324. [CrossRef]

5. Saini, R.K.; Keum, Y.-S. Carotenoid extraction methods: A review of recent developments. Food Chem. 2018, $240,90-103$. [CrossRef]

6. Poojary, M.M.; Barba, F.J.; Aliakbarian, B.; Donsì, F.; Pataro, G.; Dias, D.A.; Juliano, P. Innovative alternative technologies to extract carotenoids from microalgae and seaweeds. Mar. Drugs 2016, 14, 214. [CrossRef]

7. Shi, J. Lycopene in tomatoes: Chemical and physical properties affected by food processing. Crit. Rev. Biotechnol. 2000, 20, 293-334. [CrossRef] [PubMed] 
8. Ortiz, D.; Ferruzzi, M.G. Identification and quantification of carotenoids and tocochromanols in sorghum grain by highperformance liquid chromatography. In Sorghum; Zhao, Z.-Y., Dahlberg, J., Eds.; Humana Press: New York, NY, USA, 2019; pp. 141-151.

9. Sen, S. The chemistry and biology of lycopene: Antioxidant for human health. Int. J. Adv. Life Sci. Res. 2019, 2, 8-14. [CrossRef]

10. Mendelová, A.; Fikselová, M.; Mendel, L. Carotenoids and lycopene content in fresh and dried tomato fruits and tomato juice. Acta Univ. Agric. Silvic. Mendel. Brun. 2013, 61, 1329-1337. [CrossRef]

11. Sahu, K.K.; Chattopadhyay, D. Genome-wide sequence variations between wild and cultivated tomato species revisited by whole genome sequence mapping. BMC Genom. 2017, 18, 430. [CrossRef]

12. Lado, J.; Zacarias, L.; Rodrigo, M.J. Regulation of Carotenoid biosynthesis during fruit development. Carotenoids Nat. 2016, 79, 161-198. [CrossRef]

13. Mariutti, L.R.; Mercadante, A.Z. Carotenoid Esters in Foods: Physical, Chemical and Biological Properties (Carotenoid Esters in Foods); Royal Society of Chemistry: London, UK, 2019.

14. Londoño-Giraldo, L.; Baena-Pedroza, A.; Martinez-Seidel, F.; Corpas-Iguarán, E.; Taborda-Ocampo, G. Gone wild: Integration of antioxidative, physicochemical, volatilomic and sensorial profiles ratify rustic relatives of cherry tomato as ideal mating partners. Sci. Hortic. 2020, 277, 109814. [CrossRef]

15. Londoño-Giraldo, L.M.; Gonzalez, J.; Baena, A.M.; Tapasco, O.; Corpas, E.J.; Taborda, G. Selection of promissory crops of wild cherry-type tomatoes using physicochemical parameters and antioxidant contents. Bragantia 2020, 79, 169-179. [CrossRef]

16. Olives Barba, A.I.; Camara Hurtado, M.; Sanchez Mata, M.C.; Fernandez Ruiz, V.; Lopez Saenz de Tejada, M. Application of a UV-vis detection-HPLC method for a rapid determination of lycopene and b-carotene in vegetables. Food Chem. 2006, 95, 328-336. [CrossRef]

17. Bueno, M.; Vitali, C.; Martínez, J.D.S.; Mendiola, J.A.; Cifuentes, A.; Ibañez, E.; Herrero, M. Compressed $\mathrm{CO}_{2}$ technologies for the recovery of carotenoid-enriched extracts from Dunaliella salina with potential neuroprotective activity. ACS Sustain. Chem. Eng. 2020, 8. [CrossRef]

18. Gallego, R.; Martínez, M.; Cifuentes, A.; Ibáñez, E.; Herrero, M. Development of a green downstream process for the valorization of Porphyridium cruentum biomass. Molecules 2019, 24, 1564. [CrossRef]

19. Britton, G.; Liaaen-Jensen, S.; Pfander, H. Carotenoids; Springer: Berlin, Germany, 2004.

20. van Breemen, R.B.; Dong, L.; Pajkovic, N.D. Atmospheric pressure chemical ionization tandem mass spectrometry of carotenoids. Int. J. Mass Spectrom. 2012, 312, 163-172. [CrossRef]

21. Gupta, P.; Sreelakshmi, Y.; Sharma, R. A rapid and sensitive method for determination of carotenoids in plant tissues by high performance liquid chromatography. Plant Methods 2015, 11, 5. [CrossRef]

22. Mercadante, A.; Rodrigues, D.; Petry, F.; Barros Mariutti, L. Carotenoid esters in foods-A review and practical directions on analysis and occurrence. Food Res. Int. 2017, 99, 830-850. [CrossRef]

23. Dzakovich, M.; Gas-Pascual, E.; Orchard, C.J.; Sari, E.N.; Riedl, K.; Schwartz, S.J.; Francis, D.M.; Cooperstone, J.L. Analysis of tomato carotenoids: Comparing extraction and chromatographic methods. J. AOAC Int. 2019, 102, 1069-1079. [CrossRef]

24. Ghislain, T.; Faure, P.; Michels, R. Detection and monitoring of PAH and oxy-PAHs by high resolution mass spectrometry: Comparison of ESI, APCI and APPI source detection. J. Am. Soc. Mass Spectrom. 2012, 23, 530-536. [CrossRef]

25. Stommel, J.R.; Haynes, K.G. Inheritance of betacarotene content in the wild tomato species Lycopersicon cheesmanii. J. Hered. 1994, 85, 401-404. [CrossRef]

26. Lewinsohn, E.; Sitrit, Y.; Bar, E.; Azulay, Y.; Ibdah, M.; Meir, A.; Yosef, E.; Zamir, D.; Tadmor, Y. Carotenoid pigmentation affects the volatile composition of tomato and watermelon fruits, as revealed by comparative genetic analyses. J. Agric. Food Chem. 2005, 53, 3142-3148. [CrossRef] [PubMed]

27. Ciriminna, R.; Fidalgo, A.; Meneguzzo, F.; Ilharco, L.; Pagliaro, M. Lycopene: Emerging production methods and applications of a valued carotenoid. ACS Sustain. Chem. Eng. 2015, 4, 643-650. [CrossRef]

28. Liu, Y.; Sherry Roof, S.; Ye, Z.; Barry, C.; van Tuinen, A.; Vrebalov, J.; Bowler, C.; Giovannoni, J. Manipulation of light signal transduction as a means of modifying fruit nutritional quality in tomato. Proc. Natl. Acad. Sci. USA 2004, 101, 9897-9902. [CrossRef] [PubMed]

29. Rambla, J.L.; Tikunov, Y.M.; Monforte, A.J.; Bovy, A.G.; Granell, A. The expanded tomato fruit volatile landscape. J. Exp. Bot. 2014, 65, 4613-4623. [CrossRef] [PubMed]

30. Ronen, G.; Carmel-Goren, L.; Zamir, D.; Hirschberg, J. An alternative pathway to $\beta$-carotene formation in plant chromoplasts discovered by map-based cloning of Beta and old-gold color mutations in tomato. Proc. Natl. Acad. Sci. USA 2000, 97, 11102-11107. [CrossRef]

31. Fraser, P.D.; Truesdale, M.R.; Bird, C.R.; Schuch, W.; Bramley, P.M. Carotenoid biosynthesis during tomato fruit development. Plant Physiol. 1994, 105, 405-413. [CrossRef] [PubMed]

32. Ronen, G.; Cohen, M.; Zamir, D.; Hirschberg, J. Regulation of carotenoid biosynthesis during tomato fruit development: Expression of the gene for lycopene epsilon-cyclase is down-regulated during ripening and is elevated in the mutant Delta. Plant J. 1999, 17, 341-351. [CrossRef]

33. Sajilata, M.; Singhal, R.; Kamat, M. The Carotenoid pigment zeaxanthin-A review. Compr. Rev. Food Sci. Food Saf. 2008, 7, 29-49. [CrossRef] 
34. Ma, L.; Yan, S.-F.; Huang, Y.-M.; Lu, X.-R.; Qian, F.; Pang, H.-L.; Xu, X.-R.; Zou, Z.; Dong, P.-C.; Xiao, X.; et al. Effect of lutein and zeaxanthin on macular pigment and visual function in patients with early age-related macular degeneration. Ophthalmology 2012, 119, 2290-2297. [CrossRef] [PubMed]

35. Giorio, G.; Yildirim, A.; Stigliani, A.L.; D'Ambrosio, C. Elevation of lutein content in tomato: A biochemical tug-of-war between lycopene cyclases. Metab. Eng. 2013, 20, 167-176. [CrossRef] [PubMed]

36. Lewinsohn, E.; Sitrit, Y.; Bar, E.; Azulay, Y.; Ibdah, M.; Meir, A.; Yosef, E.; Zamir, D.; Tadmor, Y. Not just colors—Carotenoid degradation as a link between pigmentation and aroma in tomato and watermelon fruit. Trends Food Sci. Technol. 2005, 16, 407-415. [CrossRef]

37. Havaux, M. Carotenoids as membrane stabilizers in chloroplasts. Trends Plant. Sci. 1998, 3, 147-151. [CrossRef]

38. Aizawa, K.; Liu, C.; Tang, S.; Veeramachaneni, S.; Hu, K.-Q.; Smith, D.E.; Wang, X.-D. Tobacco carcinogen induces both lung cancer and non-alcoholic steatohepatitis and hepatocellular carcinomas in ferrets which can be attenuated by lycopene supplementation. Int. J. Cancer 2016, 139, 1171-1181. [CrossRef]

39. Rugkong, A.; McQuinn, R.; Giovannoni, J.J.; Rose, J.K.C.; Watkins, C.B. Expression of ripening-related genes in cold-stored tomato fruit. Postharvest Biol. Technol. 2011, 61, 1-14. [CrossRef]

40. Tieman, D.; Zhu, G.; Resende, M.F.R., Jr.; Lin, T.; Nguyen, C.; Bies, D.; Rambla, J.L.; Beltran, K.S.O.; Taylor, M.; Zhang, B.; et al. A chemical genetic roadmap to improved tomato flavour. Science 2017, 355, 391-394. [CrossRef] 